changes in fat They can, however, be eliminated by the use of atmospheres free from oxygen and containing a high carbon dioxide content, and by this method bacon can now be successfully stored for months as compared with weeks previously possible.

Other improvements in the science and art of food storage and transport are dependent upon the use in special cases and for special purposes of atmospheres containing regulated traces of such gases as ozone, ethylene and ammonia. Ozone removes undesirable substances from storage atmospheres, such as the 'volatiles' of ripening fruit, which in too high a concentration are harmful to the fruits themselves or 'taint' other products stored afterwards or simultaneously in the same space. Ozone can also exercise a retarding effect on bacterial and mould growth. Ethylene is used specifically to stimulate in fruits the climacteric change alluded to above, so that large quantities can be brought uniformly to the optimum stage of ripeness at the time desired. Ammonia retards the germination of spores of decay organisms always unavoidably present to a greater or less extent on the surface of all kinds of fresh foodstuffs.

In broad retrospect, the past twenty-five years appear as an era in which scientific and practical skill has achieved remarkable results in extending the scope of storage and transport as regards the prevention of wastage. By a continuance of the same general methods-that is to say, progressive and intensive scientific analysis of the properties and behaviour of foodstuffs of all kinds and the close linking of practical application with new discovery - the next twenty-five years should see, I think, as great an advance in the quality of products as the past twenty five years has witnessed in their quantity and variety.

\title{
Special Steels
}

\author{
By Sir Robert Hadfield, Bt., F.R.s.
}

\section{INTRODUCTION}

$\mathrm{T}$ $\mathrm{HE}$ author regards it as a privilege to be invited to review in these columns the general progress of special or alloy steels during the first twenty-five years of His Majesty's reign. His pleasure in accepting this invitation is further increased by the fact that he had last year the honour of being one of the deputation from the Iron and Steel Institute to present His Majesty with the Bessemer Gold Medal, which he graciously accepted. In doing so, His Majesty was following a precedent established by Queen Victoria and continued by King Edward VII, to whom in 1906 the author himself had the honour of presenting the Medal on behalf of the Iron and Steel Institute. Thus for three generations the Royal Family has demonstrated its concern and interest for the welfare and progress of the iron and steel industry, upon which the prosperity of our country and its position in the world so largely depends.

Within the limits of space here available, it is not possible to give anything approaching a complete survey of advances in the vast field of special and alloy steels during the past quarter of a century. The story is in fact one which begins much earlier and shows during this notable period of industrial activity the vigorous expansion of the era of alloy steels, which at its commencement had become well established but was then com- paratively young. In 1929 the world's output of steel, then at its maximum production, was 120 million tons, of which no less than about 6 million tons represented alloy steels.

In reviewing progress in this period of twentyfive years it is necessary, therefore, to take account both of those newer alloy steels which it has seen initiated and also of the developments which have taken place in the use of those which had already found practical application.

The author's discovery and invention of manganese steel in 1882, as expressed by so many well-known metallurgists, marked the dawn of the age of high alloy steels. The extraordinary and valuable results then obtained led him to investigate in many other directions this hitherto practically unknown field, and later he was followed by numerous other investigators. To-day manganese steel, with modern improvements in manufacture, is used throughout the world in increasing quantities and for a greater variety of purposes than ever before. In addition, there have been developed corrosion- and heat-resisting steels, high-speed tool steels, special steels for armaments and ordnance, special structural steels, high tenacity steels, and steels with remarkable magnetic properties, whether as regards low energy losses in electrical machinery and apparatus, specially high permeability at low magnetisations, or special suitability for permanent 
magnets, as the case may be. The arts of peace have been served in no less measure than the needs of national defence, and progress has been astonishingly rapid in all the branches of metal lurgical knowledge concerned.

\section{Manganese Steel}

Much progress has been made, and many difficulties overcome, in the production and applications of manganese steel since the original specimens of this material were exhibited by the author at the reading of his first paper on this subject before the Institution of Civil Engineers in 1887, that is, almost exactly forty-eight years ago. This alloy, now known throughout the world as the Hadfield manganese steel, consists of a non-magnetic alloy of iron with from 11 to 14 per cent of manganese and about 1.25 per cent carbon, and remains one of the most remarkable ferrous materials yet produced, whether from the point of view of practical application or scientific interest.

Whilst the general progress of metallurgy has brought about improvement in the actual manufacture of the material, as also its heat treatment which plays such an essential part in the full development of its qualities, this important alloy, manganese steel, remains exactly the same as when originally invented in $\mathbf{1 8 8 2}$.

\section{Silicon Steel}

The history of the development of this remark able steel, invented by the writer in the latter portion of the nineteenth century, and how the early difficulties attending its introduction and production, including the best and most suitable proportions to be used of the element silicon, also heat treatment, were surmounted, are given very fully in his book "Metallurgy and its Influence on Modern Progress".

Since its first employment early in the present century, silicon steel has become of the highest importance in the electrical industry by its use in transformers, generators, motors and many other purposes. Without the use of silicon steel, the efficiency of electrical generation and transformation would be seriously lower than at present and many modern designs of electrical plant would be physically impossible owing to the increased energy losses.

The hysteresis loss of this steel is initially about two thirds that of unalloyed iron, and actually decreases during a period of years in service. Its high electrical resistance, about six times that of iron, is also of great advantage in minimising losses due to eddy currents, while its maximum magnetic permeability is about 25 per cent higher than that of iron.

\section{Corrosion-Resisting Steels}

The remarkable developments in corrosionresisting steels, as also in heat-resisting steels to be referred to later, have taken place entirely within the past twenty-five years. Several varieties of specialised types have been developed to meet different requirements. There are many applications in chemical and other industries for materials combining resistance to corrosion with the mechanical properties of steel, that is, apart from the use of some of these special alloy steels for domestic and ornamental applications. No single steel yet developed meets all possible requirements in this field, but many special steels have been perfected, and from these it is generally possible to choose one which is effective against any particular one or more of the many corrosive agencies encountered in industry.

The simpler and original type of corrosionresisting steel, usually termed 'stainless' steel, established by Brearley, containing 12-14 per cent of chromium and from about 0.05 per cent up to about 0.40 per cent of carbon, also still higher percentages such as 16-18 per cent of chromium, according to the purpose for which they are intended, have valuable mechanical properties, and are specially suitable for applications in which the corrosive action is of the ordinary kind, that is, due to air and water. For chemical and other applications where a wider range of resistance to corrosion is required, the steels most generally used are of the nickel-chromium type, low in carbon and with from about 12-20 per cent of chromium and about 7-12 per cent of nickel, and in certain cases also small additions of elements such as tungsten, molybdenum and titanium, and other elements are being investigated such as columbium. These materials are now available in castings, forgings, rolled sheets or bars, tubes and wire; also by machining, pressing, welding and other methods of assembly they can be fabricated into practically any form desired.

The development of non-rusting steel covers an exceedingly wide field and those specially interested in the history describing its origin and rise are recommended to refer to Chapter ix of the author's book "Faraday and his Metallurgical Researches" where the later development of alloy steels is dealt with.

Steels of this type are now used widely for 
tanks, pans and other parts of chemical or other manufacturing equipment exposed to corrosive media too numerous to be mentioned individually, including many of the most commonly encountered acids and corrosive salts. There is also large employment $f_{\text {or }}$ these steels for decorative purposes where high polish is required. For other applications, further and more special types of corrosion-resisting steels have been developed.

One of these, for example, is useful in the sulphate house of coal and coke by-product recovery plants, owing to its resistance to dilute sulphuric acid. Also it finds many applications in sugar refineries owing to its resistance to acid calcium phosphate and other chemicals employed ; and it is specially valuable in food industries, being unaffected by the dilute solutions of phosphoric acid contained in chemical foods.

In a very different field, the use of a corrosionresisting special steel for the reinforcements of the masonry in the preservation of St. Paul's Cathedral, London, suggests that such material will be employed to an increasing extent, ensuring the permanence of our historic buildings as necessity arises. It will doubtless be a satisfaction to all concerned with the metallurgy of iron that the special steels so employed and supplied by three Sheffield firms are associated in such an important capacity with the safety of the cathedral in which the Royal Silver Jubilee Thanksgiving Service is to be held.

In the construction of new buildings also high tensile non-corrodible steel is being used, as in the case of certain structural members in the new library of the University of Cambridge.

\section{Heat-Resisting Steels}

Almost contemporary with the development of corrosion-resisting steels has been the recognition and utilisation of the merits of heat-resisting steels. There are, in general, ferrous alloys with high nickel and chromium contents, variable in amount according to the properties required in the products. In some cases, the iron content barely exceeds 50 per cent.

The term 'heat-resisting', as applied to steels, implies resistance to oxidation and other forms of corrosion at high temperatures, while retaining a high degree of mechanical strength. Materials fulfilling these conditions find many important applications, including the valves of internal combustion engines, rotors of gas turbines, mechanical parts of furnaces of all kinds, reaction vessels for coal-hydrogenation, and many other uses requiring mechanical reliability combined with freedom from oxidation and scaling. Developments in this field have been so numerous that it is impossible here to do more than indicate their variety and importance. The following examples are, therefore, to be taken merely as representative and by no means exhaustive.

Cast iron parts formerly used in mechanical stokers in the Canadian Pacific Steamship Company's vessels of the Beaver class, operating with air preheated to $310^{\circ} \mathrm{F}$., were found to require replacement after every second round trip. The parts exposed to the severest conditions, such as tuyères, grate plates, slicing bars and extension plates, were, therefore, made of heat-resisting steel, and the grates were then found to be in perfect condition after a year's continuous service. Similar examples are provided in many other directions and, to take one at the other end of the scale, claw bars of heat-resisting steel in a certain type of domestic hot-water boiler are still in perfect condition after two years service, where new cast iron bars were formerly required every three or four months. This is only one of many instances.

The exhaust valves of internal combustion engines are, specially where high efficiency is aimed for, exposed to most difficult conditions as regards temperature, mechanical stress and liability to scaling and erosion. Here again, special heatresisting steels come to the rescue, and exhaust valves of such material have contributed to successive world speed records on land, water and in the air. Similar conditions apply in the case of the rotors of exhaust gas turbines, in which applications equal success has been attained.

For the vessels used in modern high-pressure high-temperature chemical processes, heat-resisting qualities must be combined with resistance to chemical action, and here again the conditions are being successfully met.

The applications of these new alloy steels are, in fact, so numerous and important that they will probably have as important an influence on the progress of engineering and the economics of industry as that exerted by the earlier alloys, manganese steel and silicon steel, in their particular spheres.

\section{Special Steels for Armour and Ordnance}

Without ceasing for a moment to regret the waste and folly of wan, it is impossible to ignore the important contributions to national defence resulting from the applications of special steels in armour, projectiles and other munitions during 
the War. Then, and, in fact, throughout the particular period under review, the rivalry between armour and projectile continued with steady improvement in each. However, the reference made here to this subject can only be brief, though without doubt our nation must continue to supplement its work by continued efforts if national security is to be preserved.

One of the most striking applications of alloy steel in the War, and one to which it is very appropriate to make present reference owing to its humanitarian aspect, was the use of manganese steel for the helmets of our soldiers and most of our allies. Though commonly known as 'tin hats', these helmets were of the much sterner material known universally as the Hadfield manganese steel, and there can be no question that very large numbers of our brave soldiers owed their lives to the remarkable toughness and resistance to shrapnel fire of this extraordinary material with its non-magnetic qualities most useful in many cases.

\section{Special Steels for Other Purposes}

At least a passing reference must also be made to high tenacity steels, large steel forgings of extraordinary weight and size, special steels for steam turbines and steam fittings, high-speed tool steels, in which great advances have been made, special magnetic steels and alloy steels for general engineering and constructional purposes. Nor should it be forgotten that there have been important advances in the quality of carbon steels, which are strictly speaking alloy steels, for, of all the elements alloyed with iron, carbon is in many respects the most powerful and remarkable in its effects.

Alloy steels possessing high breaking strengths up to 100 tons per sq. in. and above have been used by engineers for some time past, and there has been steady progress during recent years in the improvement of the quality of such high-tenacity alloy steels, specially as regards toughness and resistance to shock and vibration.

In many of the largest steam turbines on land and sea, and even in more ordinary installations where there may seem to be no special liability to erosion and corrosion, a special alloy of iron high in its nickel and chromium contents is used for the blading, with great advantage in the maintenance of high steam economy, this alloy being highly resistant to erosion and completely noncorrodible under all the conditions experienced by steam turbine blading. For example, already turbines of no less than 7 million horse power in total capacity are now bladed in whole or in part with such special steel.

One of the most interesting developments in modern high-speed tool steels, specially in view of the fact that manganese steel was formerly considered to be practically unmachinable, is the discovery of alloy steels which will drill and cut water-toughened manganese steel, thus making possible a further extension in the many applications of this exceedingly useful material.

Great progress has been made in special steels for permanent magnets and in steels of very high permeability at low inductions; also in new nonmagnetic alloys of iron. Again, there have been important developments in the use of alloy steels for general constructional purposes, for example in the hulls of large vessels where reduction of weight is an important consideration. Many other instances might be mentioned, if space permitted, of improvements in alloy steels which have greatly advanced engineering and industrial practice since the year 1910 .

\section{IMPORTANCE OF RESEARCH}

If there is one outstanding lesson that has been brought out by metallurgical progress in general and made possible the rise of alloy steels in particular, it is the importance of continual research. Also this research, specially where alloy steels are concerned, must be over as wide a field as possible.

As an instance it may be mentioned that the laboratories of the author's firm, as well as those of most modern steel works, have for many years used for routine testing as well as original investigations, equipment for every kind of testchemical, mechanical and physical-with special apparatus for carrying out tensile, bending, endurance, impact, hardness, electrical conductivity, magnetic permeability, hysteresis, measurement of temperatures from the lowest to the highest, the determination of thermal change points and other tests. In a single week as many as 12,000 pyrometric observations have been made, and equipment for the microscopic examination and photomicrography of steels at all powers up to 5,000 and even 8,000 diameters is continually in use.

In any appreciation of the great and increasing importance of metallurgical research during the past twenty-five years account must be taken of the part played by our universities in the training of metallurgical students, and in many instances conducting valuable research investigations. The special duties and responsibilities of the research laboratories maintained 
by firms, and working in direct touch with the conditions and requirements of commercial development, can never be fully undertaken by other institutions or organisations. At the same time, metallurgists owe a great debt of gratitude to the universities. As an example, it may be mentioned that the training and research work carried out in the laboratories of the Applied Science Department of the University of Sheffield are worthy of the highest traditions of the city, and the establishment of metallurgy as an independent faculty with, quite recently, a special founding course and degrees in foundry science is but one instance of the way in which the authorities are keeping in the forefront of metallurgical progress. The importance of research facilities is equally recognised at other universities, each in its own sphere, but in regard to ferrous metallurgy the University of Sheffield naturally occupies a special position and is second to none in the world.

Outside the many and valuable researches carried out at the various universities of Great Britain reference must certainly be made to the important work being carried on continuously by the National Physical Laboratory, originally under the able guidance of Sir Richard Glazebrook, and now that of Sir Joseph Petavel, to whom and his staff, composed of men of scientific eminence, great credit is due. This great national establishment is now supported by large annual grants, aided by Parliament through the Royal Society and the Department of Scientific and Industrial Research.

\section{The Future}

Finally, as will have been gathered in the reading of this article, the continued and increasing use of alloy steels in their many forms is most certainly assured. The great value of such products can almost be said to be beyond computation in view of the services they render, and modern civilisation could not be sustained by any other means ; they may, therefore, be justly said to be beyond any adequate expression in terms of money.

It is scarcely realised how largely further advances of present modern civilisation depend upon alloy steels. Take these away and our modern civilisation could certainly not exist, at any rate, on anything like its present high plane, and we should in many respects be cast back to the comparatively unsatisfactory conditions of more than a century ago.

It is entirely the production and use of alloy steels which have rendered practicable the bringing into being of engineering and other constructions which would not otherwise have been possible, whether in their employment on land or sea or in the air.

One useful alloy after another, new or improved, takes its place in the eivilisation which it advances and thereafter it is indispensable unless indeed a still better material can be discovered. Progress far beyond the bounds which could be foreseen twenty-five years ago has already been achieved, and the rate of such advance appears likely to continue undiminished. Therein lie challenge, inspiration and encouragement for those of the younger generation.

\section{Progress in Radio Communication}

\section{By Prof. E. V. Appleton, f.R.S., Wheatstone Professor of Physics, King's College, London}

$\mathrm{T}^{\mathrm{T}}$ is a matter worthy of note that the remarkable progress of radio communication during the last quarter of a century has proceeded largely from the exploitation of the properties of that late. nineteenth century discovery, the free electron. For it is no exaggeration to say that practically all the instrumental progress of the period is connected in some way with that wonderful device, the three-electrode electron tube, while we now realise that the spectacular annihilation of distances in round-the-world communication by wireless is only brought about by the beneficent influence of free electrons at high atmospheric levels. Another significant feature of the period is that radio developments have had an unusually marked influence on human intercourse for, through broad. casting, there has been introduced a new and permanent feature of social and cultural enlightenment while, by way of the oversea wireless telephone, the different parts of the Empire have been brought into a closer unity which from time to time has been sealed by personal messages of greeting from His Majesty the King to all his subjects throughout the world.

In 1910 the utility of wireless communication was regarded as being largely concerned with increasing the safety of life at sea. Public interest was, in 1912 for example, stirred by the case of the Titanic which, with some 3,000 people on board, struck an iceberg on her maiden voyage 